\title{
A PATATIVA DO NORTE VAI ÀS ARCADAS: OS 100 ANOS DA VISITA PRESIDENCIAL DE UM INTERNACIONALISTA AO LARGO DE SÃO FRANCISCO
}

\author{
'PATATIVA DO NORTE' GOES TO THE ‘ARCADAS': THE 100TH ANNIVERSARY OF THE \\ PRESIDENTIAL VISIT OF AN INTERNATIONALIST TO 'LARGO DE SÃO FRANCISCO’
}

Marcilio Toscano Franca Filho*

\begin{abstract}
Resumo:
Na tarde da segunda-feira, 29 de agosto de 1921, o então Presidente da República Epitácio Pessoa faz uma visita oficial à Faculdade de Direito do Largo de São Francisco, a convite do Centro Acadêmico XI de Agosto. A visita tem um especial significado, afinal Pessoa é, antes do político e homem de Estado, um respeitado jurista dedicado ao Direito Internacional. Para comemorar o centenário dessa visita, o presente texto republica, com uma breve nota introdutória, o discurso pronunciado por Epitácio naquela ocasião.

Palavras-chave: Epitácio Pessoa. História da Faculdade de Direito de São Paulo. História do Brasil. República Velha.
\end{abstract}

\begin{abstract}
:
On the afternoon of Monday, August 29 $9^{\text {th }}$, 1921, the President of the Republic Epitácio Pessoa paid an official visit to the Faculty of Law of São Paulo, as an invitation of the XI de Agosto Student Association. The visit has a special meaning. In fact, Mr. Pessoa is, besides a politician and statesman, a respected jurist dedicated to International Law. To commemorate the centenary of this visit, this text republishes, with a brief introductory note, the speech delivered by Mr. Pessoa at that day.
\end{abstract}

Keywords: Epitácio Pessoa. History of the Faculty of Law of São Paulo. History of Brazil. The Brazilian 'Old' Republic.

\footnotetext{
Membro do Executive Council da International Law Association (ILA, Londres, Reino Unido), sócio do Instituto Hispano-Luso-Americano de Derecho Internacional (IHLADI) e árbitro suplente do Tribunal Permanente de Revisão do MERCOSUL (Assunção, Paraguai). Doutor em Direito pela Universidade de Coimbra (Portugal). Pós-doutorado em Direito no Instituto Universitário Europeu (Florença, Itália), onde foi Calouste Gulbenkian Fellow. Professor do Centro de Ciências Jurídicas da Universidade Federal da Paraíba e Procurador-Chefe da Força Tarefa do Patrimônio Cultural do Ministério Público de Contas da Paraíba. Foi Professor Visitante do Departamento de Direito da Universidade de Turim, Itália, aluno da Universidade Livre de Berlim (Alemanha), estagiário-visitante do Tribunal de Justiça das Comunidades Europeias, Consultor Jurídico (Legal Advisor) da Missão da ONU em Timor-Leste (UNOTIL) e Senior Legal Advisor do Programa de Construção de Capacidades em Gestão de Finanças Públicas do Ministério das Finanças de Timor-Leste e do Banco Mundial (PFMCBP).
} 
Breve nota introdutória

De trem, vindo do Rio de Janeiro e a caminho da capital paulista, onde faria uma visita oficial, o então Presidente da República Epitácio Lindolfo da Silva Pessoa ${ }^{1}$ faz uma parada em Taubaté, às 20 h do dia 18 de agosto de 1921. A comitiva presidencial é saudada vigorosamente por milhares de pessoas, segundo a crônica dos jornais da época. Ao agradecer às demonstrações públicas de apreço de autoridades locais e populares, Pessoa confidencia um dado pouco conhecido de sua biografia: trinta e sete anos antes, recém-formado bacharel pela Faculdade de Direito do Recife, por muito pouco não iniciou a sua vida pública como promotor de justiça em Taubaté. Terminou optando por assumir a promotoria de Bom Jardim (PE), perto do Recife e de sua Paraíba natal, mas "Era, pois, essa recordação, mais um motivo para agradecer a carinhosa manifestação que se lhe fazia” (EXCURSÃO..., 1921, p. 4).

Por onde passava, Pessoa fazia questão de ressaltar sua afeição pelo direito e sua estima pela profissão jurídica, que abraçou nos múltiplos papéis que exerceu como professor universitário, promotor público, advogado, árbitro, Ministro da Justiça, Ministro do Supremo Tribunal Federal, Procurador-Geral da República, Deputado Federal constituinte, Senador, representante do Brasil na Conferência de Versalhes, membro da Comissão de Jurisconsultos Americanos, Presidente da República e juiz da Corte Permanente de Justiça Internacional de Haia.

No dia seguinte à sonora passagem por Taubaté, 19 de agosto de 1921, desde cedo uma ruidosa aglomeração aguardava o comboio presidencial na Estação da Luz. Ao desembarcar na capital de São Paulo, por volta das onze e meia da manhã, Pessoa e a comitiva presidencial foram recepcionados por uma multidão e pelo então presidente do Estado, Washington Luiz, acompanhado de inúmeras autoridades civis, militares, consulares e eclesiásticas. O Largo de São Francisco enviou uma delegação de grande prestígio para recepcionar o jurista-presidente, o "primeiro magistrado da Nação": estavam lá o Diretor Herculano de Freitas, o secretário Júlio Maia, além dos Professores Francisco Morato, Spencer Vampré e Frederico Steidel, representando a douta Congregação (EXCURSÃO..., 1921, p. 4).

Dois dados bem podem dar conta da magnitude que alcançou a recepção a Pessoa em São Paulo. O primeiro indicador é o fato de que, à chegada, fora da Estação da Luz, um contingente de 5.500 homens do Exército e da Força Pública tentava organizar uma multidão de “delirantes exclamações" (EXCURSÃO..., 1921, p. 4). ${ }^{2}$ O segundo

Umbuzeiro (PB), 23 de maio de 1865 - Petrópolis (RJ), 13 de fevereiro de 1942.

2 O Paiz, edição de quinta-feira, 18 de agosto de 1921, p. 4, indicava que fora decretado feriado municipal na sexta-feira, data da chegada de Epitácio a São Paulo. 
sinal foi a construção de um grandiloquente Arco do Triunfo, no início da Av. Tiradentes, especialmente concebido por Ramos de Azevedo para recepcionar o Presidente da República paraibano. As dimensões do pórtico impressionavam: 28 metros de altura por 27 de metros de largura, com um vão de 10 metros de largura por 14 de altura (O ARCO..., 1921, p. 4).

A visita presidencial aos paulistas estendeu-se por longos dez dias. A extensa programação incluiu muitas inaugurações, recepções, almoços, concertos de gala no Teatro Municipal, uma partida de futebol entre o C. A. Paulistano e o Palestra (placar final de 0x0) e visitas a Santos, Campinas e Ribeirão Preto. A imprensa cobria tudo em detalhes.

Na tarde da segunda-feira, 29 de agosto de 1921, um dos pontos altos da agenda presidencial teve lugar na capital paulista. Aquiescendo a um convite do Centro Acadêmico XI de Agosto, Epitácio Pessoa, ex-professor da Faculdade de Direito do Recife e Doutor pela mesma "Casa de Tobias Barreto", dirigiu-se a uma sessão solene na Faculdade de Direito de São Paulo, acompanhado de Washington Luís e vasta comitiva, "onde foi entusiasticamente recebido pelos lentes e numerosos acadêmicos" (VISITA..., 1921, p. 6).

O evento tinha um significado particular: mais que política, aquela era, antes de mais, uma visita acadêmica. Era o jurista respeitado e professor reconhecido que prestava honras à faculdade co-irmã à sua Alma Mater pernambucana. A lista dos docentes presentes à sessão solene incluía Herculano de Freitas, Diretor da Faculdade, Amâncio de Sousa Carvalho, Gama Cerqueira, Estevam de Almeida, Pacheco Prates, Cândido Motta, José Ulpiano, Raphael Sampaio, Spencer Vampré e Frederico Steidel, todos devidamente trajados com a beca acadêmica que, décadas antes, o mesmo Pessoa, quando Ministro da Justiça, definira para as faculdades de direito nacionais (VISITA..., 1921, p. 6). ${ }^{3}$

Epitácio chegava às Arcadas com a reputação consolidada de grande internacionalista. Adepto que era do Grand Tour, as longas jornadas culturais e formadoras, aprendeu desde cedo que viajar lhe garantia repertório, network e visão global. Desde jovem empreendera longas e múltiplas peregrinações à Europa, onde desenvolvera a aptidão (em verso e prosa) para o francês, o italiano, o alemão e o inglês (GABAGLIA, 1951, p. 121 et seq.; PARDELLAS, 2018, passim.; FRANCA FILHO; FRANCA, 2020, p. 267-275). Bacharel, logo interessou-se pelos assuntos e pelos temas do direito comparado, do direito internacional e das relações internacionais.

3 O Decreto n. 2.226 , de $1^{\circ}$ de fevereiro de 1896, definiu os estatutos das Faculdades de Direito da jovem república brasileira. Os arts. 103 e 105 daquele diploma atribuíam ao Ministro da Justiça e dos Negócios Interiores a competência para definir o figurino dos bacharéis e dos doutores em direito. Coube ao elegante Epitácio Pessoa, em 18 de maio de 1900, quando à frente daquele Ministério, instituir o modelo das vestes acadêmicas nacionais. (FRANCA FILHO, 2020). 
Esses interesses apenas aumentaram enquanto foi Deputado Federal constituinte e Ministro da Justiça, quando os seus contatos com questões e autoridades estrangeiras também não foram poucos - é o que apontam as suas Obras Completas em muitos dos seus vinte e cinco volumes.

Entre 1909 e 1911, quando ministro do Supremo Tribunal Federal, Pessoa redige, a pedido do Barão de Rio Branco, um alentado Projeto de Código de Direito Internacional Público, para as chamadas Conferências Pan-Americanas de Estados - embrião institucional que, depois, daria origem à atual Organização dos Estados Americanos (OEA). ${ }^{4}$ Apesar de concebido há mais de um século, entre 1909 e 1911, o Projeto de Código de Direito Internacional Público de Pessoa permanece atualíssimo e até vanguardista na escolha e no trato de muitas questões.

O êxito da empreitada codificadora - elogiada por Antônio de Bustamante, Alejandro Alvarez, Brown Scott, J. M. Yepes, V. Korestsky, A. de Lapradelle, Truyol y Serra, entre tantos outros, de ontem e de hoje, - levaria Epitácio à presidência da Junta Internacional de Jurisconsultos Americanos, reunida no Rio de Janeiro, de 26 de junho a 19 de julho de 1912. Entre 1909 e 1912, ainda, Epitácio contribui com o Itamaraty nos fundamentos jurídicos de disputas territoriais com o Peru. Fronteiras eram um tema de sua predileção e Epitácio também arbitraria conflitos de divisas entre o Amazonas e o Pará, São Paulo e Minas Gerais, Goiás e Minas Gerais e entre Paraná e São Paulo nos anos seguintes (LEWIN, 1995, p. 71; PESSOA, 1961, passim). $^{5}$

$\mathrm{Na}$ sua vasta atividade como advogado e jurisconsulto, ofertou ainda diversos pareceres sobre questões de direito internacional, tais como a validade do divórcio de estrangeiro no Brasil; os efeitos da nacionalidade brasileira concedida a estrangeiros; a repercussão de sentença falimentar francesa; a homologação de sentença estrangeira; os interesses de cidadãos alemães no Brasil durante a Grande Guerra; sociedade brasileira no estrangeiro; monopólios comerciais internacionais; contratos internacionais; sujeição de estrangeiros à jurisdição nacional etc. - mais uma vez, é o que sinalizam as suas Obras Completas.

Em 24 de outubro de 1914, ao lado de Rui Barbosa, Lauro Müller, Lafayette Rodrigues Pereira, Sá Viana, Conde de Affonso Celso, Rodrigo Octávio, Pedro Lessa, Amaro Cavalcanti, Clóvis Bevilaqua, entre outros estudiosos, participa no Rio de Janeiro da criação da Sociedade Brasileira de Direito Internacional, que lhe atribui o título de "sócio-fundador".

\footnotetext{
$4 \quad$ O texto integral do projeto epitaciano além de um comentário doutrinário detalhado podem ser encontrados em (FRANCA FILHO; MIALHE; JOB, 2013).

5 O papel de árbitro seria desempenhado ainda por Epitácio em inúmeros casos laudos.
} 
Antes de chegar a São Paulo, naquele agosto de 1921, Pessoa implementou, nos meses iniciais do seu mandato na Presidência da República, uma vigorosa política externa, reformando o Itamaraty, reconhecendo Estados, abrindo embaixadas e missões diplomáticas no exterior, recepcionando Chefes de Estado e outras autoridades estrangeiras, propondo e subscrevendo importantes acordos internacionais, restabelecendo relações diplomáticas interrompidas, participando da Liga das Nações.

Por tudo isso, quem é saudado, "sob uma vibrante salva de palmas", pelo Professor Spencer Vampré, em nome da Faculdade de Direito do Largo de São Francisco, e pelo estudante Oscar Stevenson, em nome do XI de Agosto, naquele 29 de agosto de 1921, é, portanto, um experiente Professor de Direito Internacional com grande intimidade com os temas jurídicos e políticos globais (VISITA..., 1921, p. 6). O homenageado é o jurista catedrático que mereceu do Professor Herculano de Freitas, Diretor da Faculdade, as seguintes palavras:

Não ha aqui, sr. presidente, um anmo lectivo em que reiteradamente não venha o vosso nome à baila, já em materia constitucional, ${ }^{6}$ em que emparelhaes com os mestres, já no Direito Internacional Publico que vos deve serviços relevantes, e esse primoroso Projecto de Codigo de Direito Internacional Publico, obra prima no genero, a rivalizar com o que, de melhor, se tem escripto no extrangeiro. Os que, como vós, estudam profundamente os problemas jurídicos, têm préviamente assegurada a immortalidade nas escolas de direito. Passam os annos impiedosos sobre todos nós, cobrem-se da poeira do esquecimento as nossas pequeninas vaidades de hoje; mas, os que bem serviram o seu paiz, na tribuna e no livro, no ensino e no Parlamento, pelo verbo e pela acção, hão de ficar sempre rememorados no coração dos moços. Sr. presidente, recordai que estamos aqui deante do futuro do Brasil, porque estamos deante dos moços que são o futuro, o mais esclarecido, o mais numeroso, o mais incorruptível, o mais soberano dos tribunaes que nos hão de julgar. A mocidade desta Faculdade vos acclama, e vos saúda, e a sua Congregação, pela minha fraca voz, se junta, cheia de jubilo, a estas merecidas homenagens. Sede

6 Epitácio também adorava os temas constitucionais. Enfrentou-os várias vezes na advocacia, na ProcuradoriaGeral da República, em seguidas arbitragens e no Supremo Tribunal Federal. Jovem ainda, Secretário-Geral do governo estadual de Venâncio Neiva, na Paraíba, redigiu um inovador projeto de constituição para o estado. Anos depois, em 1928, quando seu sobrinho João Pessoa era o presidente da Paraíba, escreveu um segundo projeto para servir de base para as discussões da Assembleia Legislativa. Em 1921, na Presidência da República, sob a vigência da constituição de 1891, foi pioneiro ao levantar a tese das "normas constitucionais inconstitucionais" em uma mensagem dirigida ao Senado da República. O clássico de Otto Bachof sobre esse tema, "Verfassungswidrige Verfassungsnormen?", só seria publicado na Alemanha em 1951. 
bemvindo na Faculdade de Direito de S. Paulo. (VISITA..., 1921, p. 6).

Ao tomar a palavra, Pessoa, conhecido como "A Patativa do Norte", em razão dos seus dotes retóricos, pronuncia o discurso a seguir transcrito, "delirantemente aclamado pelos estudantes".

\section{O Discurso do Presidente Epitácio Pessoa}

\section{FACULDADE DE DIREITO DE SÃO PAULO ${ }^{7}$}

(Agosto de 1921)

"Sinceramente, eu não imaginava que a simples visita para que fui convidado pela amabilidade do Centro Acadêmico Onze de Agosto se convertesse nesta imponente solenidade. Diante da majestade deste ambiente, sinto-me realmente confundido e perturbado, e não acho expressões para traduzir com fidelidade todo o meu desvanecimento pela honra insigne que me confere a douta Congregação da Faculdade de Direito de São Paulo, recebendo-me em seu seio e associando-se às generosas manifestações de apreço de que me faz objeto a bondade dos seus discípulos. Tampouco posso dizer quanto me penhoram os ilustres colegas, Srs. Drs. Herculano de Freitas e Spencer Vampré, cumulando-se de gentilezas e de conceitos que só posso atribuir à simpatia e amizade que tive a fortuna de inspirar-lhes.

Dir-vos-ei, por isso, apenas, Srs. Doutores, que, dentre as numerosas manifestações de simpatia que tenho recebido desde a minha chegada a esta terra generosa, não é esta a que menos me toca o coração, partindo, como parte, daqueles que representam o escol da intelectualidade paulista, daqueles para quem o Direito, em todos os seus aspectos sociais, tem sido, como para mim, uma preocupação absorvente da vida; daqueles a quem está confiada a missão delicada e temerosa de construir, aparelhar e consolidar as colunas, sobre as quais, amanhã, devem repousar a integridade, os brios e a honra do Brasil. (Muito bem, palmas prolongadas).

É sempre possuído de um profundo sentimento de confiança e simpatia que me ponho em contato com a mocidade. É que eu vejo na mocidade (e não me suponham que há nas minhas palavras uma simples figura de retórica), é que eu vejo na mocidade a principal, a mais poderosa, a mais brilhante dentre as forças propulsoras do progresso da Nação; é que eu ouço borbulhar no seu seio o mais acendrado espírito de devotamento e de sacrifício; é que eu sinto palpitar no seu peito o coração mesmo da Pátria, onde esta vem beber alento e vida e haurir, a largos sorvos, os santos entusiasmos, feitos de abnegação e

A íntegra do discurso, com esse título, está transcrito em Pessoa (1956, p. 500-503). 
de coragem, que, nas épocas culminantes da nossa História, nos têm conduzido, vitoriosos, às conquistas da liberdade e da democracia. (Palmas prolongadas, muito bem).

Ao penetrar neste recinto, Senhores, o que me dominou não foi somente a emoção de me encontrar neste edifício legendário, iluminado há quase um século pelas mais vivas fulgurações da inteligência e do saber, e de onde uma soberba irradiação de eloquência, de integridade e de trabalho se tem espelhado por toda a nação, pela voz dos oradores, pela casuística dos advogados, pelas sentenças dos juízes, os mais nobres postulados do direito e da justiça. (Palmas prolongadas). Ao penetrar neste recinto, o que me dominou não foi somente a saudade de outro instituto congênere, que guarda também as mais formosas tradições de patriotismo, onde formei o meu espírito e aprendi a amar a justiça, como primeira condição de vida, como o mais sólido fundamento das instituições sociais, como o atributo mais elevado e característico da superioridade moral do homem. (Longos aplausos).

Ao penetrar neste recinto, tive também a impressão de que o futuro do Brasil perpassa por entre estas vetustas paredes, a sua sombra divaga por estes corredores solitários, às vezes cheia de apreensões e de receios, mas, quase sempre, rica de entusiasmos e de esperanças, porque, Senhores, é aqui que moureja a mocidade, é aqui que se afinam os seus sentimentos de abnegação e de civismo, é aqui que se acrisola o seu culto pela liberdade, é aqui que se formam os cidadãos a quem amanhã o Brasil entregará a defesa da sua integridade, os surtos do seu progresso, os melindres da sua vida internacional (Muito bem, muito bem. Prolongada salva de palmas).

Ao penetrar aqui, ainda outro sentimento me dominou, e este me encheu de desvanecimento e de orgulho: o de que não somente as classes conservadoras de São Paulo, as pessoas mais representativas do primeiro Estado da Federação, me vêm trazer o testemunho do seu apoio; é também a mocidade da sua Capital, que vem fazer justiça ao esforço, ao desinteresse e ao patriotismo com que tenho procurado servir ao meu País. (Aplausos prolongados.) Nem a mocidade me acolheria com estas manifestações de cordialidade e de estima, se algum dia eu houvesse mentido aos meus deveres de cidadão ou fugido às responsabilidades do meu cargo. (Muito bem, muito bem).

Os aplausos que recebo trazem-me grande conforto, despertam-se as forças necessárias para prosseguir na senda que venho trilhando em meio de dificuldades sem número, mas com passo firme e resoluto; os aplausos que me dirige a mocidade acordam novas energias no meu espírito para exaltar no coração dos moços o sentimento fecundo do amor da Pátria.

Estranharam já que seja este o meu tema predileto, sempre que tenho ocasião de falar em público. É porque a preocupação constante do meu espírito, estimulado de um lado pelas observações de minhas viagens e açulado de outro pela indiferença dos meus compatrícios, é que não temos feito tudo quanto podemos e quanto devemos pela grandeza 
e pela glória da nossa Pátria. (Muito bem, palmas). Quanto mais viajo, mais me sinto filho do Brasil, mais confiança tenho nas suas possibilidades, mais clara se me apresenta a visão do seu futuro. É por isso que me esforço por estimular o patriotismo dos moços, que são as mais justas esperanças da Nação, sangue novo e sadio, destinado a acender-lhe nas veias a sede do progresso, o culto da justiça, o amor da liberdade. (Aplausos prolongados).

Já alguém me chamou de "nacionalista". Não pode haver qualificativo mais grato ao meu coração de brasileiro. (Muito bem). Mas o meu nacionalismo, como já tive ocasião de dizer em público, não é feito de ódios e prevenções contra o estrangeiro, cuja colaboração nos é necessária, cujo auxílio desejamos para a exploração das nossas inesgotáveis riquezas latentes; o meu nacionalismo é feito de amor e de carinho por tudo quanto se relaciona com o Brasil, de zelo pelo seu nome, de esforço pelo seu progresso, de sonhos pela sua glória. (Muito bem, palmas). O meu nacionalismo figura para mim um Brasil novo, rico e poderoso; o seu vastíssimo território rasgado de caminhos de ferro, os seus rios imensos coalhados de barcos, uns e outros conduzindo para os seus portos, convertidos nos mais vastos empórios comerciais da terra, os produtos variados do seu seio exuberante; a instrução difundida até as mais baixas camadas sociais; as suas artes, as suas ciências, as suas indústrias levadas ao apogeu do desenvolvimento; a sua palavra recebida com acatamento e respeito pelas mais poderosas nações do mundo nas conferências internacionais; a sua raça unida, robusta e laboriosa, procurando fazê-lo cada dia mais forte, mais culto e mais belo. (Prolongada salva de palmas).

Moços, amai assim o Brasil; amai-o desse amor que absorve a personalidade inteira; amai-o desse amor que se faz de abnegação e de sacrifícios, de devotamento e de ternura; amai-o e o vosso amor o iluminará, o vosso amor o transformará em breve nessa grande nacionalidade dos sonhos, respeitada e temida, progressiva e fecunda, gloriosa e feliz.

(Uma delirante ovação abafou as últimas palavras do Sr. Presidente da República)".

Epitácio Pessoa 


\section{Duas Curiosidades Finais}

Quatro anos depois daquela visita presidencial, o v. 22 da Revista da Faculdade de Direito de São Paulo (1925, p. 75-83) publica um "Discurso que deveria ter sido pronunciado na Faculdade de Direito de S. Paulo na recepção do Dr. Epitacio Pessôa, e que não o foi por motivo de força maior", de autoria do Professor Braz de Sousa Arruda. Não há ali, porém, a indicação de qual teria sido, de fato, o tal "motivo de força maior", mas ficou o registro impresso em favor do

grande estadista, o illustre mestre, o internacionalista de reputação mundial, o publicista inegualavel, o tribuno sempre vigilante, o advogado sempre attento, cheio de dedicação pela causa que lhe foi confiada, (...) um homem integro, intemerato, incorruptivel, exemplar, de passado que era penhor seguro de seu futuro proceder, (...) Conserve Deus por muitos annos o grande homem que honra sua patria, e que é parte para que ella seja respeitada no extrangeiro, e tenha sua vida interna sabiamente dirigida.

Em 1950, Francisco Pati, antigo estudante do Largo de São Francisco entre 1919 e 1923, recupera a memória daquele dia ao publicar “O Espírito das Arcadas”, sob os auspícios da Associação dos Antigos Alunos da Faculdade de Direito de São Paulo. Suas vivas memórias acadêmicas registram um dia agitado:

A visita de Epitácio Pessoa à Faculdade de Direito, em 1921, não foi uma questão pacífica entre professores e alunos. Iniciara-se no Brasil, sob o seu governo, o ciclo das revoluções. (...) Temia-se que a presença da "Patativa do Norte" no velho casarão colonial do largo de São Francisco provocasse manifestações de desagrado ou de irreverência, incompatíveis, num e noutro caso, com a dignidade do alto mandato exercido pelo ilustre paraibano. (...) Nunca vi tanta gente na cidade como no dia em que se anunciou a visita do presidente da República ao 'Velho Convento'. A rua de São Bento era um formigueiro em polvorosa. No largo de São Francisco não cabia uma agulha. A Faculdade agigantavase. Tinha-se a impressão de que a visita de Epitácio Pessoa aos moços era um ato de contrição. Ampliava-se no tempo e no espaço a força consagradora da simpatia estudantina. (...) Depois de uma rápida peregrinação em 'lugares sagrados' da escola (Arcadas, sala n. ${ }^{\circ}$ 2, túmulo de Júlio Frank), a sessão solene na 'sala dos retratos'. Gente à cunha. Todo o mundo queria ouvir a 'Patativa do Norte'. Falava-se da sua oratória como de um fenômeno. Esperava-se, além do mais, que o discurso do chefe do governo aos moços contivesse revelações sensacionais, ou, pelo menos, grandes promessas. Herculano de Freitas dispôs os visitantes 
segundo o protocolo interno da Academia e deu a palavra ao orador dos estudantes. Oscar Stevenson encaminhou-se para a tribuna e fez a saudação do estilo. Epitácio Pessoa levantou-se para agradecer. Foi então que, na sala vergando ao peso de tantas responsabilidades — tradição acadêmica e dignidade da função pública ali encarnada na pessoa do chefe da nação - se ouviu, antes que o orador pudesse ter iniciado o seu discurso, uma exclamação curta, estridente, jocosa, uma exclamação que cortou o ar como uma chicotada, deixando a assistência atônita:

\section{- Aí, Tio Pita!}

'Tio Pita' era a alcunha de Epitácio. Naquela hora, em lugar de uma alcunha poderia ter sido um epitáfio. Mas a assistência, colhida de surpresa, não teve sequer o tempo de rir. E isso salvou a festa. (...) A alcunha de 'Patativa do Norte' assentava-lhe ainda como uma luva. Que orador prodigioso era Epitácio Pessoa! (...) A eloqüência de Epitácio Pessoa estava, a um tempo, nas palavras e nos gestos. Esqueciase, quando na tribuna, do cargo que exercia. Cantava e gesticulava. Os períodos brotavam-lhe espontaneamente musicais. Percebia-se que era um homem habituado ao convívio dos grandes mestres da literatura. Via-se, antes de mais nada, que tinha o hábito de raciocinar em voz alta. A frase, sempre escorreita e impecável sob o ponto de vista gramatical, dizia exatamente o que queria dizer. Nem mais nem menos. Mas a voz é que era tudo nele. Quando, alguns anos mais tarde, vim a saber que a voz de Aristides Briand, como o plectro de Orfeu, aquietava as paixões na Câmara de Paris, não fiquei com ciúme dos franceses. Nós tivéramos, também, num passado recente, a voz de Epitácio Pessoa! Quando terminou a visita, ninguém mais se lembrava das apreensões de horas antes. Ninguém mais se lembrava, sobretudo, daquele "Aí, Tio Pita!" com que um estudante gaiato pretendera estimular a hostilidade contra a "Patativa". Fizemos a Epitácio Pessoa uma das maiores manifestações de que há notícia nos anais da querida escola do largo de São Francisco. O único estudante que não pôde dar excessiva expansão ao seu entusiasmo foi Oscar Stevenson, cujo corpo, modelado pelo fraque de Aristides de Toledo, era como se estivesse dentro de um cilício. (PATI, 1950).

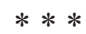

Cabo Branco (PB), primavera de 2020. 


\section{Referências}

A VIAGEM do presidente da Republica a S. Paulo. O Paiz, Rio de Janeiro, anno 37, n. 13.451, 20 ago. 1921. Disponível em: http://memoria.bn.br/pdf/178691/per178691_1921_13451.pdf.

ARRUDA, Braz de Sousa. Discurso que deveria ter sido pronunciado na Faculdade de Direito de S. Paulo na recepção do Dr. Epitacio Pessôa, e que não o foi por motivo de força maior. Revista da Faculdade de Direito de São Paulo, São Paulo, v. 22, p. 75-83, 1925.

BRASIL. Decreto n. 2.226, de $1^{\circ}$ de fevereiro de 1896. Approva os estatutos das Faculdades de Direito da Republica. Collecção das Leis da Republica dos Estados Unidos do Brazil. Rio de Janeiro: Imprensa Nacional, 1898. Disponível em: https://bd.camara.leg.br/bd/bitstream/handle/ bdcamara/18721/colleccao_leis_1896_parte2.pdf?sequence=2\&isAllowed=y.

EXCURSÃO Presidencial: a viagem do Dr. Epitacio Pessoa a S. Paulo. O Paiz, Rio de Janeiro, anno 37, n. 13.453, 20 ago. 1921. Disponível em: http://memoria.bn.br/pdf/178691/ per178691_1921_13453.pdf.

FRANCA FILHO, Marcílio Toscano. Do têxtil ao texto: os 20 anos do direito da moda. GEN Jurídico, São Paulo, 14 jul. 2020. Disponível em: https://bit.ly/34Xmb3d.

FRANCA FILHO, Marcílio Toscano; FRANCA, Alessandra Correia Lima Macedo. Os epigramas da Haia: direito internacional e poesia em Epitácio Pessoa e Hugo Grotius. In: LAUAND, Jean; CAETANO, João Relvão (org.). Pensar, ensinar e fazer justiça: estudos em homenagem a Paulo Ferreira da Cunha. São Paulo: Kapenke, 2020. v. 2, p. 267-274.

FRANCA FILHO, Marcílio Toscano; MIALHE, Jorge Luís; JOB, Ulisses da Silveira (org.). Epitácio Pessoa e a codificação do direito internacional. Porto Alegre: Fabris, 2013.

GABAGLIA, Laurita Pessoa Raja. Epitácio Pessoa (1865-1942). Rio de Janeiro: José Olympio, 1951. v. 1. p. 121 et seq.

LEWIN, Linda. The papers of Epitácio Pessoa: an archival note and a personal comment. LusoBrazilian Review, Madison, v. 32, n. 1, p. 69-82, 1995. p. 71.

O ARCO do Triumpho. Correio Paulistano, São Paulo, n. 20.882, 20 ago. 1921. Disponível em: http://memoria.bn.br/pdf/090972/per090972_1921_20882.pdf.

PARDELlAS, Carlos Alberto Pessôa. Epitacio Pessôa: na Europa e no Brasil. Brasília: FUNAG, 2018.

PATI, Francisco. O espirito das Arcadas. São Paulo: Associação dos Antigos Alunos da Faculdade de Direito de São Paulo, 1950.

PESSOA, Epitácio. Conferência da paz: diplomacia e direito internacional. Rio de Janeiro: Instituto Nacional do Livro, 1961. 
PESSOA, Epitácio. Presidência da República: mensagens especiais: vetos, discursos, notas e despachos. Rio de Janeiro: Instituto Nacional do Livro, 1956. p. 500-503.

VISITA à Faculdade de Direito: enthusiasticas manifestações ao Sr. presidente da Republica: os discursos pronunciados. Correio Paulistano, São Paulo, n. 20.890, 30 ago. 1921. Disponível em: http://memoria.bn.br/pdf/090972/per090972_1921_20890.pdf. 